\title{
Delorme's Procedure: An Effective Treatment for a Full-Thickness Rectal Prolapse in Young Patients
}

\author{
Mohammad Sadegh Fazeli, Ali Reza Kazemeini, Amir Keshvari, Mohammad Reza Keramati \\ Department of Surgery, Imam Khomeini Medical Center, Tehran University of Medical Sciences, Tehran, Iran
}

Purpose: Delorme's procedure is infrequently applied in young adults because of its assumed higher recurrence rate. The aim of this prospective study was to assess the efficacy of the Delorme's technique in younger adults.

Methods: Fifty-two consecutive patients were entered in our study. We followed patients for at least 30 months. Their complaints and clinical exam results were noted.

Results: Our study included 52 patients (mean age, 38.44 years; standard deviation, 13.7 years). Of the included patients, 41 (78.8\%) were younger than 50 years of age, and $11(21.1 \%)$ were older than 50 years of age. No postoperative mortalities or major complications were noted. Minor complications were seen in 5 patients $(9.6 \%)$ after surgery. The mean hospital stay was 2.5 days. In the younger group (age $\leq 50$ years), fecal incontinence was improved in $92.3 \%$ (12 out of 13 with previous incontinence) of the patients, and recurrence was seen in $9.75 \%$ (4 patients). In the older group (age $>50$ years), fecal incontinence was improved in $20 \%$ ( 1 out of 5 with previous incontinence) of the patients, and recurrence was seen in $18.2 \%$ ( 2 patients). In $50 \%$ of the patients with a previous recurrence ( 3 out of 6 patients) following Delorme's procedure as a secondary procedure, recurrence was observed.

Conclusion: Delorme's procedure, especially in younger patients, is a relatively safe and effective treatment and should not be restricted to older frail patients. This procedure may not be suitable for recurrent cases.

Keywords: Rectal prolapse; Aged; Recurrence; Fecal incontinence

\section{INTRODUCTION}

A full-thickness rectal prolapse is a formidable and debilitating condition that needs surgical management. It can usually be easily diagnosed with a careful history and physical exam. The associated symptoms are tenesmus, incomplete evacuation, obstructed defecation, mucus discharge, bleeding, the need to manually assist in defecation by pushing in the perineum, and functional complaints like incontinence, constipation and even diarrhea.

More than 100 procedures have been described for the correc-

Received: February 11, 2013 - Accepted: March 12, 2013

Correspondence to: Mohammad Reza Keramati, M.D.

Department of Surgery, Imam Khomeini Medical Center, Keshavarz Blvd.,

Tehran 13145-158, Iran

Tel: +98-912-1147406, Fax: +98-912-1147406

E-mail:dr_morezak@yahoo.com

(c) 2013 The Korean Society of Coloproctology

This is an open-access article distributed under the terms of the Creative Commons Attribution NonCommercial License (http://creativecommons.org/licenses/by-nc/3.0) which permits unrestricted noncommercial use, distribution, and reproduction in any medium, provided the original work is properly cited. tion of rectal procidentia [1], but no clear procedure of choice exists. The aim of treatment is to repair the prolapse and to resolve functional problems like incontinence and constipation with a low complication rate, an acceptable mortality rate, and a low recurrence rate $[2,3]$. Delorme's procedure was initially described in 1900 as a technique to correct an overt rectal mucosal prolapse [4].

Perineal procedures such as the Delorme's technique are reserved for older frail patients with significant comorbidity because a higher recurrence rate is assumed when using perineal procedures [5-7]. However, the recurrence rate in younger ( $\leq 50$ years of age) patients who undergo Delorme's procedure has recently been shown to be comparable with those of transabdominal approaches [8]. Moreover, neurologic complications (including sexual or urologic disturbances) related to extensive dissection within the pelvic region have been reported in transabdominal approaches. This study was performed to investigate the effectiveness of Delorme's procedure and to review the clinical outcomes for patients who underwent that procedure, with a special focus on patients 50 years of age or younger. 


\section{METHODS}

Our study was a prospective descriptive study conducted from 2009 to 2012. Fifty-two consecutive patients who had undergone Delorme's procedure for treatment of full-thickness rectal prolapses with diameters of 2 to $12 \mathrm{~cm}$ were included in the study. Patients with a history of treatment failure with other procedures, including Delorme's procedure, were also included. Patients who had undergone a modified Delorme's procedure were excluded. Preoperational defecography was done in a group of patients, and proctoscopy, rectosigmoidoscopy or anal manometry were done selectively. A complete history, including symptoms, signs, family history, and past surgeries, was taken before the operation. Patients were considered continent if they could hold air, liquid, and solid.

Preoperative mechanical bowel preparation with a polyethylene glycol solution, preoperative administration of an antibiotic preparation of oral erythromycin or metronidazole, and administration of postoperative intravenous antibiotics (three doses) were used in all of patients. Preoperative anticoagulation therapy was administered for deep venous thrombosis prophylaxis if indicated. All the patients signed an informed consent form before surgery. Patients were positioned in the lithotomy position. Spinal anesthesia was carried out in 40 cases (77\%), and general anesthesia was done in $12(23 \%)$ according to patient's will.

The standard Delorme's procedure was used. The prolapse was fully extended, and a circumferential mucosal incision, about 2 centimeters above the dentate line, was made after injection of epinephrine solution (1:100.000) into the submucosa. The mucosa was dissected from the muscularis layer. The exposed muscular layer was then folded, and eight plicating sutures of longacting absorbable material were inserted in the muscular wall of the rectum and then gently tied. Eventually, the cut ends of the mucosa were sutured together.

The patients were usually helped out of bed the evening of the surgery and were fed orally within the first 24 hours after surgery.

Table 1. Demographic information on the patients

\begin{tabular}{lcccc}
\hline Gender & No. & Age $(\mathrm{yr})$ & Age $\leq 50 \mathrm{yr}$ & Age $>50 \mathrm{yr}$ \\
\hline Female & 20 & $37(12.28)$ & 17 & 3 \\
Male & 32 & $38.87(14.7)$ & 24 & 8 \\
All & 52 & $38.44(13.7)$ & 41 & 11
\end{tabular}

Values are presented as mean (standard deviation).

Table 2. Preoperative and postoperative incontinence in the patients

\begin{tabular}{|c|c|c|c|c|c|c|c|c|}
\hline & \multirow{2}{*}{ Before surgery } & \multicolumn{4}{|c|}{ First year after surgery } & \multicolumn{2}{|c|}{ Second year after surgery } & \multirow{2}{*}{$\begin{array}{c}\text { Third year after surgery } \\
6 \mathrm{mo}\end{array}$} \\
\hline & & $3 \mathrm{mo}$ & $6 \mathrm{mo}$ & $9 \mathrm{mo}$ & $12 \mathrm{mo}$ & $6 \mathrm{mo}$ & $12 \mathrm{mo}$ & \\
\hline Exclusive gas incontinence & 11 & 8 & 4 & 4 & 4 & 3 & 2 & 1 \\
\hline Solid incontinence & 7 & 4 & 4 & 3 & 3 & 2 & 2 & 2 \\
\hline Recurrence & & 2 & 3 & 4 & 4 & 5 & 6 & 6 \\
\hline
\end{tabular}

The discharge date was determined based on the patient's medical condition and complications. On discharge, patients were educated about dietary fiber and adequate fluids. All patients were followed up for at least 30 months postoperatively, trimonthly in the first year and then every 6 months. During the follow-up period, data were collected in the presence of a colorectal surgeon. All patients were questioned about improvements of symptoms or any complaints and were examined. A recurrence was defined as a full-thickness protrusion of the rectal wall discovered upon examination.

\section{RESULTS}

Our study included 52 patients ( 31 males and 21 males; male: female ratio, 1.47:1) (Table 1). Two of them had a family history of full-thickness rectal prolapse in their first-degree relatives. The mean hospital stay was 2.5 days. Twenty-one patients (40.3\%) had a history of past anorectal surgeries, including surgical repair of a rectal prolapse ( $\mathrm{n}=6,4$ abdominal procedures and 2 Delorme's procedures), a hemorrhoid $(\mathrm{n}=8)$, a perianal abscess or fistula $(\mathrm{n}=3)$, a pilonidal sinus $(\mathrm{n}=2)$, an anal fissure $(\mathrm{n}=1)$ or a rectovaginal fistula $(\mathrm{n}=1)$. On the preoperative pelvic examination, 23 patients $(44 \%)$ had a large prolapse (diameter, $>5 \mathrm{~cm}$ ), and 29 $(56 \%)$ had a small prolapse (diameter, $<5 \mathrm{~cm}$ ).

No perioperative deaths and no intraoperative complications were noted. Minor postoperative complications occurred in 8 patients (15.4\%); 4 patients (7.7\%) had urinary retention requiring short-term catheterization, and 4 patients (7.7\%) had minor surgical site bleeding (one after 7 days). All eight patients with minor postoperative complications were treated conservatively. No dehiscence, hematoma, cellulites or strictures were noted.

The types and prevalences of symptoms at the times of the follow-up visits are summarized in Tables 2 and 3 . Eleven of the 52 patients (21\%) had complained of exclusive gas incontinence preoperatively, and 7 of the $52(13.4 \%)$ had had solid incontinence and soiling (mucus discharge). Solid incontinence was always associated with gas incontinence. On the first follow-up visit after surgery, 12 of the patients exclusively had gas incontinence ( 2 new incidences after surgery); however, the prevalence decreased to 7 , 4 and 3 persons by the ends of the first, second and last follow-up visits, respectively. No new incidents of gas incontinence were noted at the last follow-up visit. Fecal incontinence was still present in four patients on the first follow-up visit after surgery (three with a history of incontinence before surgery), two of which were 
found to be continent on the last follow-up visit. Incontinency was resolved in $92 \%$ of the patients in the younger group and was improved in $60 \%$ of the patients in the older group (Fig. 1). The preoperative constipation and cure rates are shown in Table 3. Two of the 52 patients had had sexual complaints before surgery: a 27-year-old man with a history of impotence and dry ejaculation after an abdominal repair of a rectal prolapse and a 62-yearold man with 2 years of impotence and decreased libido and with a 4 -year history of a rectal prolapse.

In 3 of the 6 patients (50\%) with recurrence, Delorme's procedure as a secondary procedure after the primary procedure ( $2 \mathrm{ab}-$ dominal procedures and 1 previous Delorme's procedure) had failed. In the other 3, 1 of whom had had a past history of anal fissure repair, Delorme's procedure was a primary procedure. Four of the 6 patients with recurrence underwent further surgery (1 abdominal procedure, 1 Delorme's procedure, 2 Altemeire procedures); and 2 of the 6 did not desire additional treatment because of the annoyance (Kaplan-Meier curve).

\section{DISCUSSION}

Our study prospectively evaluated the anatomical and the functional outcomes (and showed the efficacy) of Delorme's procedure in patients with a full-thickness rectal prolapse. Figs. 2 to 6 depicts the procedure in detail. To our knowledge, only a few studies have been published on the efficacy of Delorme's procedure in the repair of a rectal prolapse in young patients $[8,9]$. Surgical tech-

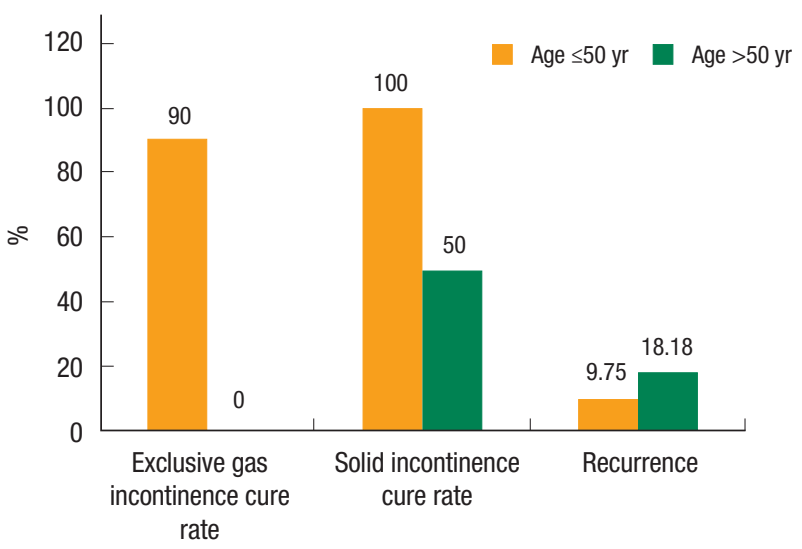

Fig. 1. Incontinence cure rate in two different age groups. niques used to repair rectal prolapse are generally categorized into perineal or abdominal approaches. Abdominal procedures mainly involve fixation of the rectum to the sacrum with or without resection of the rectum or the sigmoid colon. The method used for rectopexy may vary in different procedures. Constipation is a

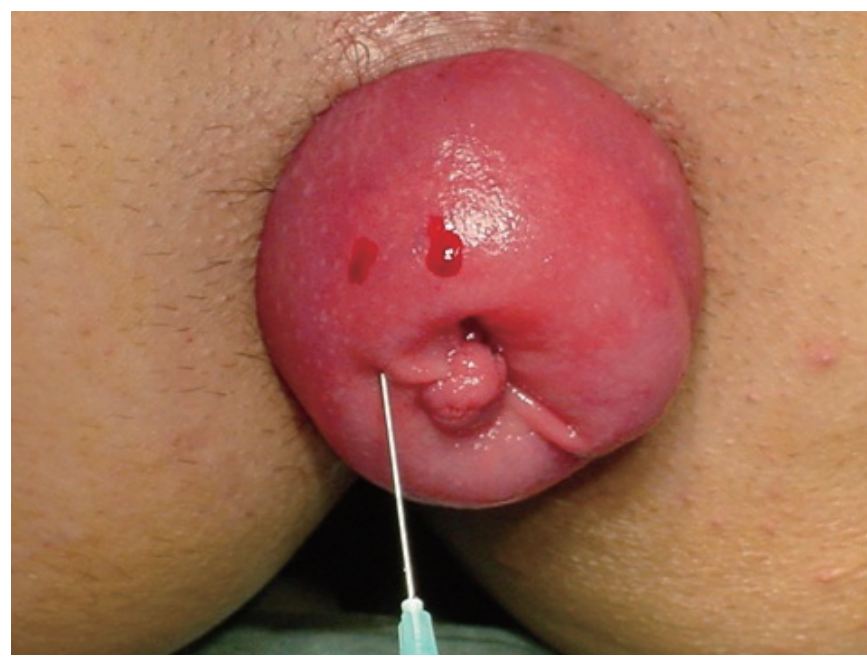

Fig. 2. Injection of epinephrine solution (1:100.000) into the submucosa in patients with a full-thickness rectal prolapsed.

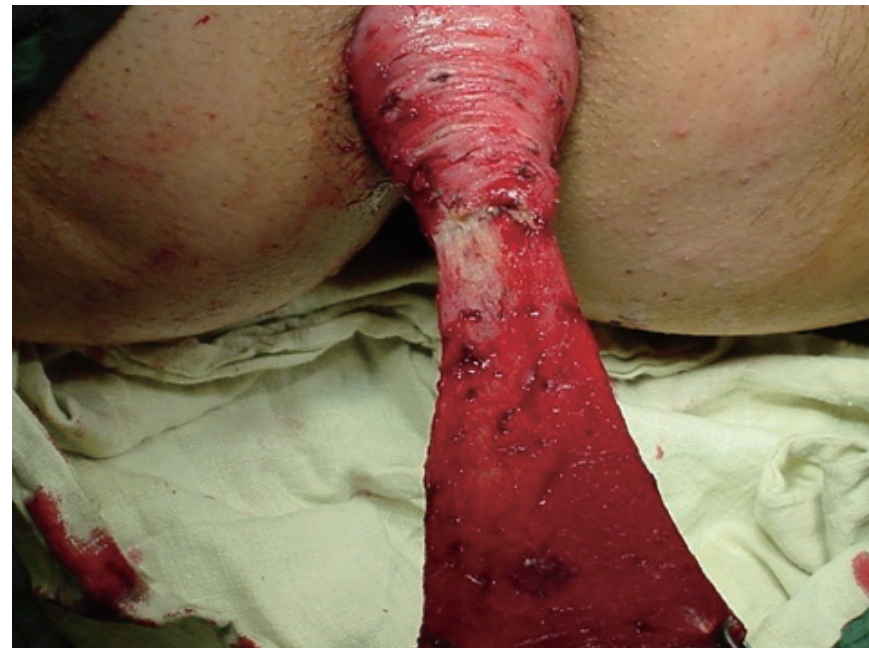

Fig. 3. Mucosal layer dissected from the muscular layer.

Table 3. Preoperative and postoperative incontinence among two age groups

\begin{tabular}{|c|c|c|c|c|c|c|c|c|c|}
\hline \multirow{2}{*}{ Complaint } & \multicolumn{3}{|c|}{ Age $\leq 50 \mathrm{yr}$} & \multicolumn{4}{|c|}{ Age $>50 \mathrm{yr}$} & \multicolumn{2}{|c|}{ Total } \\
\hline & Before delorme & Last visit & Cure rate $(\%)$ & Before delorme & Last visit & Cure rate $(\%)$ & Before delorme & Last visit & Cure rate $(\%)$ \\
\hline Exclusive gas incontinence & 10 & 1 & 90.0 & 1 & 2 & 0 & 11 & 3 & 72.7 \\
\hline Solid incontinence & 3 & 0 & 100.0 & 4 & 2 & 50.0 & 7 & 2 & 71.4 \\
\hline Constipation & 6 & 3 & 50.0 & 18 & 4 & 77.8 & 23 & 7 & 69.6 \\
\hline Visible prolapse & 41 & 4 & 9.8 & 11 & 2 & 18.2 & 52 & 6 & 11.5 \\
\hline
\end{tabular}


Volume 29, Number 2, 2013

Ann Coloproctol 2013;29(2):60-65 Coloproctology

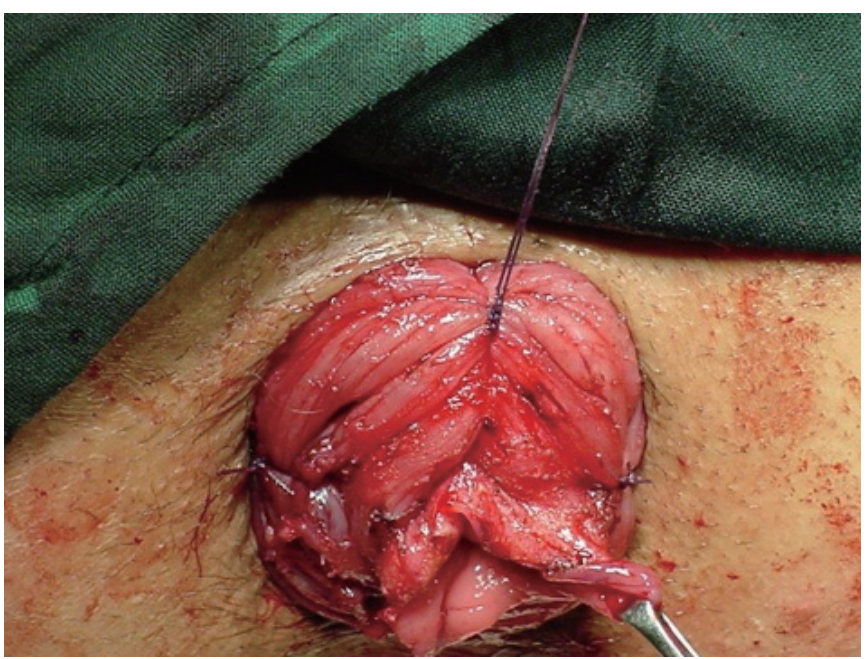

Fig. 4. Insertion of plicating sutures in the muscular wall of the rectum after dissection of the mucosa from the muscularis layer.

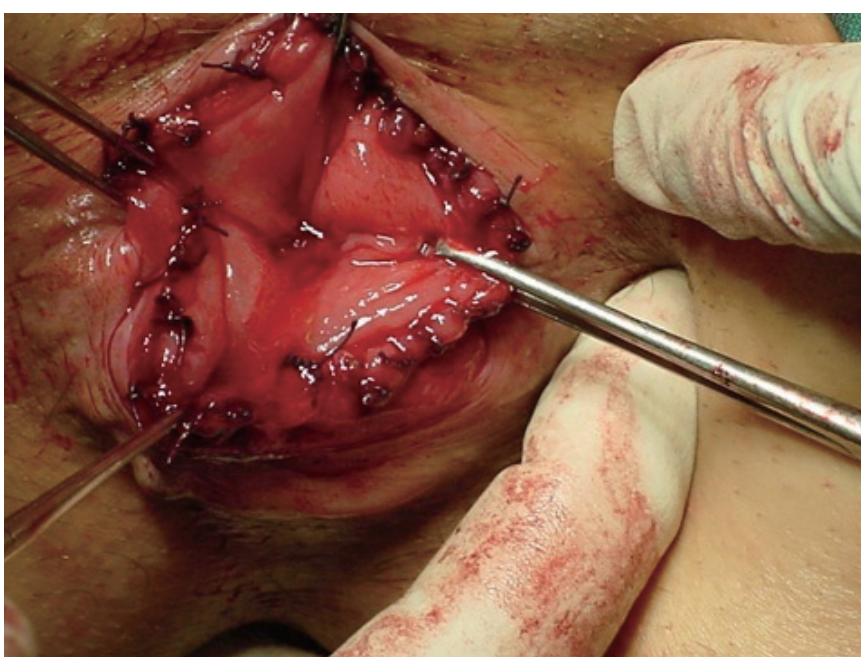

Fig. 5. Suturing the cut ends of the mucosa together.

known complication of abdominal rectopexy; however, a concomitant sigmoid resection may decrease the constipation rate [10, 11]. Bruch et al. [12] also suggested that preservation of the "lateral ligaments" might improve the postoperative constipation. In addition to the general hazards of laparatomies, these procedures involve the risk of pelvic nerve damage, which may cause sexual dysfunction in men, and adhesion formation, which may affect fertility in women. In one study, retrograde ejaculation and impotence were seen in $17.2 \%$ of the patients and were major causes of dissatisfaction after posterior rectopexy [3]. Perineal procedures have been suggested as initial options in certain groups of patients: young men in whom pelvic dissection and associated risk of injury to the pelvic nerves may hazard sexual dysfunction $[13,14]$, young nulliparous women in whom potential injury to the ovaries

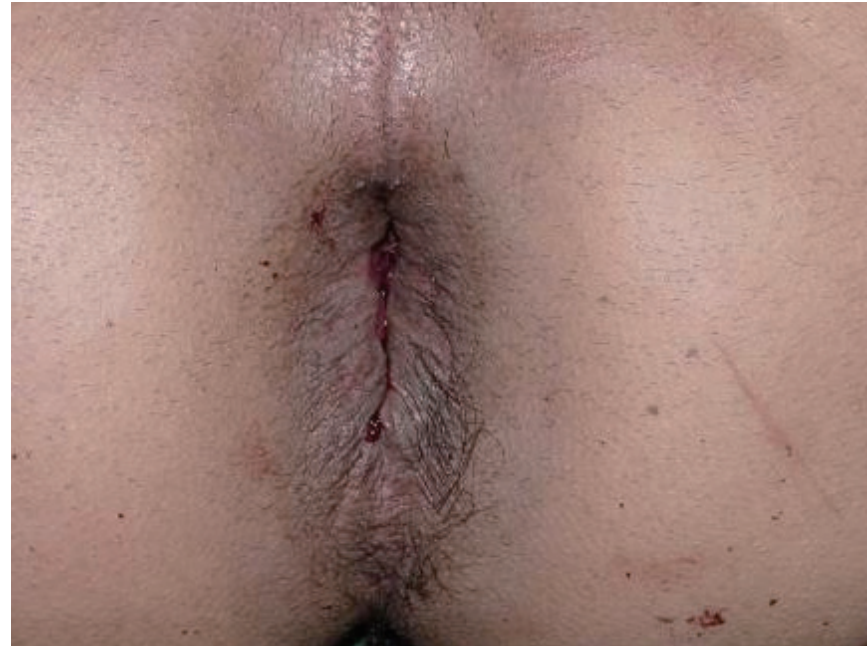

Fig. 6. Outcome following the surgery.

Table 4. Delorme's procedures for rectal prolapse

\begin{tabular}{lcccccc}
\hline Author & Year & No. & $\begin{array}{c}\text { Age } \\
\text { (yr) }\end{array}$ & $\begin{array}{c}\text { Recurrence } \\
\text { (\%) }\end{array}$ & $\begin{array}{c}\text { Inconti- } \\
\text { nence } \\
\text { improved }\end{array}$ & $\begin{array}{c}\text { Follow-up } \\
\text { period } \\
\text { (mo) }\end{array}$ \\
\hline Monson et al. [20] & 1986 & 27 & 74 & 7 & & 35 \\
Abulafi et al. [21] & 1990 & 22 & 75 & 4.5 & & 29 \\
Lechaux et al. [9] & 1995 & 41 & & 5 & 45 & \\
\hline Senapati et al. [5] & 1994 & 32 & 70 & 12.5 & & 24 \\
Oliver et al. [22] & 1994 & 41 & 82 & 22 & 58 & 47 \\
Kling et al. [7] & 1996 & 6 & 78 & 16.7 & 67 & 11 \\
Pescatori et al. [6] & 1998 & 33 & 59 & 21 & & 39 \\
Tsunoda et al. [14] & 2003 & 31 & 70 & 13 & 63 & 39 \\
Watkins et al. [18] & 2003 & 52 & 68 & 10 & 83 & 61 \\
Marchal et al. [17] & 2005 & 60 & 67 & 23 & 42 & 29 \\
\hline Lieberth et al. [8] & 2009 & 76 & 74 & 14.5 & 85 & 43 \\
& & 13 & 36 & 8 & & 57 \\
\hline
\end{tabular}

and the fallopian tubes should be avoided $[15,16]$, and frail, debilitated patients who are not suitable for a transabdominal approach.

Traditionally, the recurrence rate has been the most important issue in determining the procedure, but recently, functional outcome, operational morbidities and overall costs have been considered. So far, abdominal procedures have been thought to have lower recurrence rates $[6,10,17]$. The various available abdominal procedures have recurrence rates between $0 \%$ to $11.9 \%$ (Table 3). The recurrence rates in Delorme's procedure and the Altemeire procedure are between $0 \%$ to $16 \%$ and $4.5 \%$ to $23 \%$, respectively (Tables 4-6). The wide variability of reported recurrence rates may be due to different follow-up periods and patient selection. Prior studies reporting high recurrence rates for Delorme's proce- 
Table 5. Altemier's procedures for rectal prolapse

\begin{tabular}{lrrccc}
\hline Author & Year & No. & Age (yr) & $\begin{array}{c}\text { Recurrence } \\
(\%)\end{array}$ & $\begin{array}{c}\text { Follow-up } \\
\text { period (mo) }\end{array}$ \\
\hline Johansen et al. [23] & 1993 & 20 & & 0 & 26 \\
Agachan et al. [24] & 1997 & 32 & 75 & 12.5 & 27 \\
Kim et al. [25] & 1999 & 183 & 64 & 16 & 64 \\
Kimmins et al. [26] & 2001 & 63 & 79 & 6.4 & 20 \\
\hline
\end{tabular}

dure made its less popular and caused it to be reserved for older, medically-unfit patients [18]. Thus, many studies comparing the results of abdominal and perineal procedures suffer from selection bias. If recurrence rates are statistically corrected for age and medical condition, the differences may not be significant.

Recent studies on Delorme's procedure have reported low recurrence in young patients $[8,9]$. The recurrence rate of $9.75 \%$ in our young group is comparable with those of popular transabdominal procedures. With success rates comparable to abdominal procedures, it may be reasonable to use Delorme's procedure as the first choice in the treatment of a full-thickness rectal prolapse in all patients. However, the improvement rates varied dramatically between our groups. The functional outcomes and the complication rate in our young group were more favorable than they were in our older group, with the patients in our older group showing results similar to those in previously published reports. Delorme's procedure is a fast and easy procedure that can be carried out under any type of anesthesia (even local). Lower operative risk, lack of abdominal-surgery complications and quicker recovery make it a safe choice. There is rarely need to wait for ileus resolution, and the time interval before stool passage is often much shorter than it is in abdominal procedures [19]. The shorter hospital stay and the earlier return to work result in a lower cost. With a lower, but acceptable, incontinence improvement, reported to range from $45 \%$ to $85 \%$, and a lower postoperative constipation rate, Delorme's procedure has an encouraging functional outcome and is even used for symptomatic relief in constipated patients. Despite the efficacy of Delorme's procedure in treating a primary prolapse, the success results in secondary cases are disappointing. Some investigators have reported high recurrence rates of $47-50 \%$ for repeated Delorme's procedures [15, 17]. Surprisingly, even in our young population, the recurrence rate for the secondary procedure was $50 \%$. Consequently, an abdominal repair is suggested for further surgical treatment in recurrent cases, especially in medically-fit patients.

In conclusion, the most appropriate surgical procedure in the treatment of complete rectal prolapse is a matter of controversy. The surgeon should balance the related hazards and advantages in selecting the procedure. Our results indicate the efficacy of Delorme's procedure and its significantly better functional outcome and recurrence rate among young patients. With its minor complications, acceptable recurrence rate and good functional results, we believe that Delorme's procedure should be considered as the first
Table 6. Transabdominal resection procedures

\begin{tabular}{lccccc}
\hline Author & Year & No. & Age (yr) & $\begin{array}{c}\text { Recurrence } \\
(\%)\end{array}$ & $\begin{array}{c}\text { Follow-up } \\
\text { period (mo) }\end{array}$ \\
\hline Huber et al. [27] & 1995 & 39 & 61 & 0 & 54 \\
Cirocco and Brown [28] & 1993 & 41 & 56 & 7 & 72 \\
Madoff et al. [29] & 1992 & 6 & & 6 & 65 \\
Stevenson et al. [30] & 1998 & 30 & & 0 & 18 \\
Bruch et al. [12] & 1999 & 72 & 62 & 0 & 30 \\
Kellokumpu [31] & 2000 & 34 & & 7 & 24 \\
Marceau et al. [32] & 2005 & 28 & & 7.14 & 25 \\
Pescatori and Zbar [33] & 2009 & 42 & & 11.9 & 61 \\
\hline
\end{tabular}

choice for all patients, particularly young adults, presenting with a complete rectal prolapse. Transabdominal techniques may be considered in recurrent cases because of the high recurrence rate for secondary Delorme's procedures.

\section{CONFLICT OF INTEREST}

No potential conflict of interest relevant to this article was reported.

\section{REFERENCES}

1. Uhlig BE, Sullivan ES. The modified Delorme operation: its place in surgical treatment for massive rectal prolapse. Dis Colon Rectum 1979;22:513-21.

2. Kuijpers HC. Treatment of complete rectal prolapse: to narrow, to wrap, to suspend, to fix, to encircle, to plicate or to resect? World J Surg 1992;16:826-30.

3. Yakut M, Kaymakcioglu N, Simsek A, Tan A, Sen D. Surgical treatment of rectal prolapse. A retrospective analysis of 94 cases. Int Surg 1998;83:53-5.

4. Classic articles in colonic and rectal surgery. Edmond Delorme 1847-1929. On the treatment of total prolapse of the rectum by excision of the rectal mucous membranes or recto-colic. Dis Colon Rectum 1985;28:544-53.

5. Senapati A, Nicholls RJ, Thomson JP, Phillips RK. Results of Delorme's procedure for rectal prolapse. Dis Colon Rectum 1994;37: 456-60.

6. Pescatori M, Interisano A, Stolfi VM, Zoffoli M. Delorme's operation and sphincteroplasty for rectal prolapse and fecal incontinence. Int J Colorectal Dis 1998;13:223-7.

7. Kling KM, Rongione AJ, Evans B, McFadden DW. The Delorme procedure: a useful operation for complicated rectal prolapse in the elderly. Am Surg 1996;62:857-60.

8. Lieberth M, Kondylis LA, Reilly JC, Kondylis PD. The Delorme repair for full-thickness rectal prolapse: a retrospective review. Am J Surg 2009;197:418-23.

9. Lechaux JP, Lechaux D, Perez M. Results of Delorme's procedure 
for rectal prolapse. Advantages of a modified technique. Dis Colon Rectum 1995;38:301-7.

10. Madiba TE, Baig MK, Wexner SD. Surgical management of rectal prolapse. Arch Surg 2005;140:63-73.

11. Benoist S, Taffinder N, Gould S, Chang A, Darzi A. Functional results two years after laparoscopic rectopexy. Am J Surg 2001;182: 168-73.

12. Bruch HP, Herold A, Schiedeck T, Schwandner O. Laparoscopic surgery for rectal prolapse and outlet obstruction. Dis Colon Rectum 1999;42:1189-94.

13. Berman IR. Different strokes for different folks in repair of rectal prolapse. Dis Colon Rectum 1995;38:330.

14. Tsunoda A, Yasuda N, Yokoyama N, Kamiyama G, Kusano M. Delorme's procedure for rectal prolapse: clinical and physiological analysis. Dis Colon Rectum 2003;46:1260-5.

15. Watts AM, Thompson MR. Evaluation of Delorme's procedure as a treatment for full-thickness rectal prolapse. Br J Surg 2000;87: 218-22.

16. Hetzer FH, Roushan AH, Wolf K, Beutner U, Borovicka J, Lange J, et al. Functional outcome after perineal stapled prolapse resection for external rectal prolapse. BMC Surg 2010;10:9.

17. Marchal F, Bresler L, Ayav A, Zarnegar R, Brunaud L, Duchamp C, et al. Long-term results of Delorme's procedure and Orr-Loygue rectopexy to treat complete rectal prolapse. Dis Colon Rectum 2005;48:1785-9.

18. Watkins BP, Landercasper J, Belzer GE, Rechner P, Knudson R, Bintz M, et al. Long-term follow-up of the modified Delorme procedure for rectal prolapse. Arch Surg 2003;138:498-502.

19. Hoel AT, Skarstein A, Ovrebo KK. Prolapse of the rectum, longterm results of surgical treatment. Int J Colorectal Dis 2009;24: 201-7.

20. Monson JR, Jones NA, Vowden P, Brennan TG. Delorme's operation: the first choice in complete rectal prolapse? Ann R Coll Surg Engl 1986;68:143-6.

21. Abulafi AM, Sherman IW, Fiddian RV, Rothwell-Jackson RL. Délorme's operation for rectal prolapse. Ann R Coll Surg Engl 1990;
72:382-5.

22. Oliver GC, Vachon D, Eisenstat TE, Rubin RJ, Salvati EP. Delorme's procedure for complete rectal prolapse in severely debilitated patients. An analysis of 41 cases. Dis Colon Rectum 1994;37:461-7.

23. Johansen OB, Wexner SD, Daniel N, Nogueras JJ, Jagelman DG. Perineal rectosigmoidectomy in the elderly. Dis Colon Rectum 1993;36:767-72.

24. Agachan F, Pfeifer J, Joo JS, Nogueras JJ, Weiss EG, Wexner SD. Results of perineal procedures for the treatment of rectal prolapse. Am Surg 1997;63:9-12.

25. Kim DS, Tsang CB, Wong WD, Lowry AC, Goldberg SM, Madoff $\mathrm{RD}$. Complete rectal prolapse: evolution of management and results. Dis Colon Rectum 1999;42:460-6.

26. Kimmins MH, Evetts BK, Isler J, Billingham R. The Altemeier repair: outpatient treatment of rectal prolapse. Dis Colon Rectum 2001;44:565-70.

27. Huber FT, Stein H, Siewert JR. Functional results after treatment of rectal prolapse with rectopexy and sigmoid resection. World J Surg 1995;19:138-43.

28. Cirocco WC, Brown AC. Anterior resection for the treatment of rectal prolapse: a 20-year experience. Am Surg 1993;59:265-9.

29. Madoff RD, Williams JG, Wong WD, Rothenberger DA, Goldberg SM. Long-term functional results of colon resection and rectopexy for overt rectal prolapse. Am J Gastroenterol 1992;87:101-4.

30. Stevenson AR, Stitz RW, Lumley JW. Laparoscopic-assisted resection-rectopexy for rectal prolapse: early and medium follow-up. Dis Colon Rectum 1998;41:46-54.

31. Kellokumpu I. Surgical treatment of rectal prolapse. Duodecim 2009;125:207-14.

32. Marceau C, Parc Y, Debroux E, Tiret E, Parc R. Complete rectal prolapse in young patients: psychiatric disease a risk factor of poor outcome. Colorectal Dis 2005;7:360-5.

33. Pescatori M, Zbar AP. Tailored surgery for internal and external rectal prolapse: functional results of 268 patients operated upon by a single surgeon over a 21-year period. Colorectal Dis 2009;11: 410-9. 